\title{
A genetic interaction of NRXN2 with GABRE, SYT1 and CASK in migraine patients: a case- control study
}

Miguel Alves-Ferreira ${ }^{1,2}$, Marlene Quintas ${ }^{1,2}$, Jorge Sequeiros ${ }^{1,2}$, Alda Sousa ${ }^{1,2}$, José Pereira-Monteiro ${ }^{1 \wedge}$, Isabel Alonso ${ }^{1}$, João Luís Neto ${ }^{1}$ and Carolina Lemos ${ }^{1,2^{*}}$ (i)

\section{Abstract}

Background: Migraine is a multifactorial disorder that is more frequent (two to four times) in women than in men. In recent years, our research group has focused on the role of neurotransmitter release and its regulation. Neurexin (NRXN2) is one of the components of the synaptic vesicle machinery, responsible for connecting intracellular fusion proteins and synaptic vesicles.

Our aim was to continue exploring the role and interaction of proteins involved in the control and promotion of neurotransmission in migraine susceptibility.

Methods: A case-control study was performed comprising 183 migraineurs (148 females and 35 males) and 265 migraine-free controls (202 females and 63 males). Tagging single nucleotide polymorphisms of NRXN2 were genotyped to assess the association between NRXN2 and migraine susceptibility. The $X^{2}$ test was used to compare allele frequencies in cases and controls and odds ratios were estimated with 95\% confidence intervals. Haplotype frequencies were compared between groups. Gene-gene interactions were analysed using the Multifactor Dimensionality Reduction v2.0.

Results: We found a statistically significant interaction model $(p=0.009)$ in the female group between the genotypes CG of rs477138 (NRXN2) and CT of rs1158605 (GABRE). This interaction was validated by logistic regression, showing a significant risk effect $[\mathrm{OR}=4.78(95 \% \mathrm{Cl}: 1.76-12.97)]$ after a Bonferroni correction. Our data also supports a statistically significant interaction model $(p=0.011)$ in the female group between the $\mathrm{GG}$ of rs477138 in NRXN2 and, the rs2244325's GG genotype and rs2998250's CC genotype of CASK. This interaction was also validated by logistic regression, with a protective effect [OR $=0.08(95 \% \mathrm{Cl}: 0.01-0.75)]$. A weak interaction model was found between NRXN2-SYT1. We have not found any statistically significant allelic or haplotypic associations between NRXN2 and migraine susceptibility.

\footnotetext{
* Correspondence: clclemos@ibmc.up.pt

José Pereira-Monteiro is deceased.

'UnIGENe, IBMC - Institute for Molecular and Cell Biology; i3S - Instituto de Investigação e Inovação em Saúde, Universidade do Porto, Porto, Portugal ${ }^{2}$ ICBAS - Instituto Ciências Biomédicas Abel Salazar, Universidade do Porto, Porto, Portugal
}

C The Author(s). 2021 Open Access This article is licensed under a Creative Commons Attribution 4.0 International License, which permits use, sharing, adaptation, distribution and reproduction in any medium or format, as long as you give appropriate credit to the original author(s) and the source, provide a link to the Creative Commons licence, and indicate if changes were made. The images or other third party material in this article are included in the article's Creative Commons licence, unless indicated otherwise in a credit line to the material. If material is not included in the article's Creative Commons licence and your intended use is not permitted by statutory regulation or exceeds the permitted use, you will need to obtain permission directly from the copyright holder. To view a copy of this licence, visit http://creativecommons.org/licenses/by/4.0/. The Creative Commons Public Domain Dedication waiver (http://creativecommons.org/publicdomain/zero/1.0/) applies to the data made available in this article, unless otherwise stated in a credit line to the data. 
Conclusions: This study unravels, for the first time, the gene-gene interactions between NRXN2, GABRE - a GABA $A_{A^{-}}$ receptor - and CASK, importantly it shows the synergetic effect between those genes and its relation with migraine susceptibility.

These gene interactions, which may be a part of a larger network, can potentially help us in better understanding migraine aetiology and in development of new therapeutic approaches.

Keywords: Genetic variants, Neurexin, Synaptic vesicles, Gene-gene interaction, Neurotransmitter

\section{Background}

Although migraine is classified as one of the top 10 most disabling disorders and is the third cause of disability in under 50s, according to the World Health Organization $[1,2]$ the burden of migraine is still highly underestimated, leading to a high rate of misdiagnosis, mistreatment or even complete absence of treatment [3].

Migraine is a multifactorial disease that results from the small contributions of several genetic and environmental factors and affects more women than men (two to four times) [3]. An increased familial risk for migraine was found in several studies, including in Portuguese families, indicating that migraine has a genetic component $[4,5]$. In the last decade, 47 genetic susceptibility loci associated with migraine have been reported by genome-wide association studies (GWAS) [6]. Some of the genes present at these loci are specifically active in the brain tissues [7]. On the other hand, candidate gene association studies, including in our population, have focused on pathways related to migraine triggers and pathophysiology, namely in genes involved in the vascular and hormonal component and in the release of neurotransmitters $[8,9]$.

In the world of neurotransmitters' release, which is undeniably linked to the pathophysiology of this disease, there is a complexity of mechanisms that deserves our attention. Over the past years, we have focused on the synaptic vesicles' machinery and life-cycle, as our group identified in the Portuguese population two risk variants in the STX1A gene [10] coding for syntaxin 1A, a constituent of the SNAP REceptor (SNARE) complex, with a fundamental role in neurotransmission control. Our group also focused in other genes from this pathway with interesting results $[9,11]$.

Now, we aim to explore this pathway as there are other genes involved that should be taken into account, such as neurexin-2 (NRXN2). The neurexin family comprises three neurexin genes (NRXN1, 2 and 3), which differ in their extracellular domains, although no functional differentiation has been determined so far [12]. Neurexin variants play important roles in the central and peripheral nervous system by controlling presynaptic $\mathrm{Ca} 2+$ channels at diverse types of synapses (excitatory and inhibitory) as well as the level of their formation and differentiation [13]. Besides binding to synaptotagmin $(S Y T)$, neurexins bind to $\mathrm{GABA}_{\mathrm{A}}$-receptors and calcium/calmodulin-dependent serine protein kinase (CASK), but these interactions have not yet been studied in detail [14-16]. Gamma-aminobutyric acid (GABA) is the main inhibitory neurotransmitter in the central nervous system (CNS) [17]. Alterations in $\mathrm{GABA}_{\mathrm{A}}$-receptors trafficking, function and surface distribution have a crucial role in the modulation of neuronal excitability [18]. In our population, an involvement of $G A B A_{A}-R$ genes in migraine's susceptibility was already described [19]. Importantly, several drugs are currently used to prevent migraine through GABAmediated action [20]. CASK is a multidomain scaffolding protein that is involved in synapse targeting, regulation of gene expression [21] and interaction with presynaptic calcium channels [22]. Previously, we have provided data evidencing the role of CASK in the pathophysiology of migraine, reinforcing the role of calcium homeostasis in this neurological disorder [11].

Genetic interactions in migraine susceptibility have already been described by others as well as by our group $[19,23,24]$. We consider that the intricacy of migraine does not stem only from the action of a single or several genes, but from an entangled genetic network between them. Therefore, we aimed to further investigate the role and interaction of NRXN2, SYT1, GABRE and CASK, additional components involved in the control mechanisms of neurotransmitter release apparatus in migraine susceptibility.

\section{Material \& methods}

\section{Aim, subjects and study design}

The aim of this study was to investigate the role and interaction of NRXN2, SYT1, GABRE and CASK in migraine susceptibility. This case-control study was conducted in a sample of patients selected at the outpatient neurologic clinic at Hospital de Santo António (HISCHP), Porto. A total of 183 unrelated patients with migraine (148 females and 35 males) were included in the study, after excluding cases with familial hemiplegic migraine. As for controls (202 females and 63 males), they were all migraine-free and either healthy blood donors or women under follow-up at Department of Obstetrics and Gynecology of HIS-CHP. We matched them with cases by geographical origin and age. 
Both cases and controls underwent a diagnostic interview, using the same structured questionnaire, based on the operational criteria of the International Headache Society (HIS) $[25,26]$. The migraine clinical diagnosis of all patients was later revised by applying the ICHD-II and $\mathrm{ICDH}-3$, but no differences were found (data not shown). Additional information on other clinical diagnosis was collected allowing the exclusion of participants with potential confounding diagnoses. Women with menstrual headaches were excluded from the control group.

The Ethics Committee of HSA-CHP approved the study and participants were asked to give their written informed consent to take part in the study.

\section{SNPs selection and genotyping}

DNA extraction from blood samples were performed by standard salting-out method [27]. Saliva samples were also collected and DNA extraction have been conducted according to the ORAGENE kits manufacturer's (DNA Genotek) instructions. As shown in Table 1, for GABRE, $C A S K$ and $S Y T 1$ genes we used previous data assessed by our group $[9,11,19]$ in the same sample. For $N R X N 2$, we selected SNPs from the International HapMap Project data dump (Release 24, November 2008, on NCBI B36 assembly, dbSNP build 126) (www.hapmap.org). Then, using Haploview 4.1 [28], we selected tagging SNPs by an aggressive tagging approach at an r2 threshold of 0.80 and with a minor allele frequency (MAF) of 0.10 , capturing all the variation for NRXN2 gene (Table 1). SNP genotyping was performed using SNaPshot (Applied Biosystems). Product extension primers and SNaPshot single base extension primer sequences for the variants studied can be supplied upon enquiry.

The multiplex reactions were performed with the Multiplex PCR Master Mix (Qiagen), in conformity with

Table 1 Tagging SNPs selected for each gene

\begin{tabular}{|c|c|c|c|c|}
\hline & \multicolumn{4}{|l|}{ Gene } \\
\hline & NRXN2 & $G A B R E^{\mathrm{a}}$ & CASK $^{\mathrm{b}}$ & $S Y T 1^{c}$ \\
\hline \multirow[t]{11}{*}{ Tagging SNPs } & rs2269730 & rs5970170 & rs12857501 & rs11113980 \\
\hline & rs3825074 & rs1061418 & rs57534320 & rs3849228 \\
\hline & rs477138 & rs2256882 & rs5918267 & rs7954927 \\
\hline & rs480617 & rs1158605 & rs5918209 & rs17293059 \\
\hline & & rs1139916 & rs2998250 & rs7963801 \\
\hline & & rs1003794 & rs5918219 & rs1245766 \\
\hline & & rs5925077 & rs5918213 & rs10778573 \\
\hline & & rs2266858 & rs2244325 & rs1732664 \\
\hline & & rs2266856 & rs1150380 & rs2037743 \\
\hline & & & rs5918245 & rs2251214 \\
\hline & & & rs4827286 & rs2701566 \\
\hline
\end{tabular}

${ }^{\mathrm{a}}$ Quintas M. et al. [19]; ${ }^{\mathrm{b}}$ Quintas M [11]; ${ }^{\mathrm{c}}$ Neto J.L. [9] to the producer's guidelines. The SNaPshot reaction was executed as per the user manual and genotyped with GeneMapper $^{\text {TM }}$ (Applied Biosystems). For rs2269730, genotyping was performed by Sanger sequencing with Big Dye ${ }^{\oplus}$ Terminator Cycle Sequencing 1.1 Ready Reaction (Applied Biosystems) according to standard procedure. The SNaPshot and Sanger sequencing products were loaded in an ABI-PRISM 3130 XL genetic analyser (Applied Biosystems).

\section{Statistical analysis}

We performed a $\chi^{2}$ test to compare allele frequencies between the groups of cases and assortment of controls, odds ratios (ORs) were estimated with 95\% confidence intervals (CI), using SNPator [29]. We used Haploview 4.1 [28] to compare haplotype frequencies in cases and controls. To identify the protein interaction network with NRXN2, we used protein-protein interaction data retrieved from the STRING database v11 [30]. To obtain only reliable interactions, we considered the human interaction network by selecting only interactions with confidence scores higher than 0.9.

Additionally, we investigated the functional enrichments association related to the protein-protein interactions identified considering Gene Ontologies (GO) [31, 32] for biological processes and cellular components. Multiple comparison significance threshold was set at False Discovery Rate (FDR) $<0.05$ [33].

Based on the interactions identified in STRING, we then assessed a possible statistical interaction between variants in these gene sets: NRXN2-SYT1, NRXN2GABRE and NRXN2-CASK in migraine, using the Multifactor Dimensionality Reduction (MDR) v2.0, a software for the identification of SNP combinations related to disease susceptibility using nonparametric methods and genetic model-free procedures [34]. Permutation Testing Module (version 1.0) of MDR was used to correct for multiple testing, with a 1000-fold permutation test. Taking into account the meaningful and significant genegene interactions found by MDR we performed a, multivariable-logistic regression for those variants (considering the most frequent homozygote as the reference) to statistically validate those results. As GABRE and $C A S K$ genes are part of the $\mathrm{X}$ chromosome we split the analysis by gender. Bonferroni correction for multiple testing was used and significance was set $\alpha=0.02$ in logistic regression analyses performed with IBM SPSS Statistics software (v.24).

\section{Results}

The demographic and clinical information of the participants in the study are presented in Table 2. 
Table 2 Demographic and clinical data of patients with migraine and controls

\begin{tabular}{lll}
\hline Characteristics & Cases $(\boldsymbol{n}=\mathbf{1 8 3})$ & Controls $(\boldsymbol{n}=\mathbf{2 6 5})$ \\
\hline Gender, Female/Male & $148 / 35$ & $202 / 63$ \\
Age at observation (mean (SD)) & $36.14(12.84)$ & $36.42(12.35)$ \\
Age at onset (mean (SD)) & $19.76(11.78)$ & $\mathrm{n} / \mathrm{a}$ \\
Family history of migraine, \% & 87 & $\mathrm{n} / \mathrm{a}$ \\
\hline
\end{tabular}

SD Standard deviation

\section{NRXN2}

Our first aim was to assess association between NRXN2 SNPs and migraine susceptibility. Allele frequencies were not significantly different between cases and controls (Additional Table 1). In the global sample, no independent effects of NRXN2 were found according to multivariate logistic models (Additional Table 2).

Then, a haplotype-based association analysis was also investigated by use of NRXN2 tagging SNPs. However, no haplotype effect was detected on NRXN2 between cases and controls for any of the haplotypes evaluated (Additional Table 3).

\section{Interactions involving NRXN2}

To better characterize the contribution of NRXN2related genes to migraine variability, we explored potential protein interactions with a confidence score higher than 0.90 and supported by experiments and functional enrichments pathways. NRXN2-SYT1 and NRXN2-CASK showed a STRING interaction score of 0.95 and 0.98 , respectively. Despite STRING interaction score NRXN2$G A B R E$ is $<0.90$ (perhaps because the interaction with neurexin II is through $\mathrm{N}$-ethylmaleimide-sensitive factor (NSF)), we decided to include this interaction in the analyses since a physical and functionally interaction has been reported [14] as well as its role in migraine's susceptibility [19]. The GO analysis indicated that these protein interactions are mainly involved in neurotransmitter secretion (GO:0007269, FDR $q=4.4 \times 10-4)$, synapse part (GO:0044456, FDR $q=7.81 \times 10-6)$, and transport (GO:0006810, FDR q = 0.012).

\section{Role of gene interactions in migraine susceptibility}

We found 2 strong synergistic interactions, demonstrated by both MDR software and logistic regression analyses, between migraine susceptibility and NRXN2GABRE and NRXN2-CASK.

\section{NRXN2-GABRE}

Importantly, we discovered a substantial synergistic interaction pertaining to the female group - shown in the dendogram (Fig. 1a) - for the best model, between the genotypes CG of rs477138 (NRXN2) and CT of rs1158605 (GABRE), with a cross-validation consistency (CVC) - the amount of times the model is classified as best within validation sets [35] - was 10/10, with testing balanced accuracy (TBA) of 0.61 and $p=0.009$ after a test of 1000-fold permutations. This interaction was validated by a logistic regression, showing a significant risk effect [OR = 4.78 (95\%CI: $1.76-12.97)$ ] after a Bonferroni correction (Table 3).

\section{NRXN2-CASK}

In addition, we found a significant interaction in the female group between the GG of rs477138 in NRXN2 and the GG and CC genotypes of rs2244325 and rs2998250, respectively $(C A S K)$, with $C V C=10 / 10, T B A=0.62$ (Fig. 1b), Furthermore, the model remained significant after permutation testing $(p=0.011)$. This interaction was also validated by a logistic regression, with a protective effect $[\mathrm{OR}=0.08$ (95\%CI: $0.01-0.75)]$ (Table 3$)$. In the male group, we did not find any significant interaction for these gene pairs.

\section{NRXN2-SYT1}

Concerning NRXN2-SYT1 interaction, although MDR showed a weak interaction between these genes (TBA of 0.57; CVC of 9/10, $p>0.05$ after permutation testing),
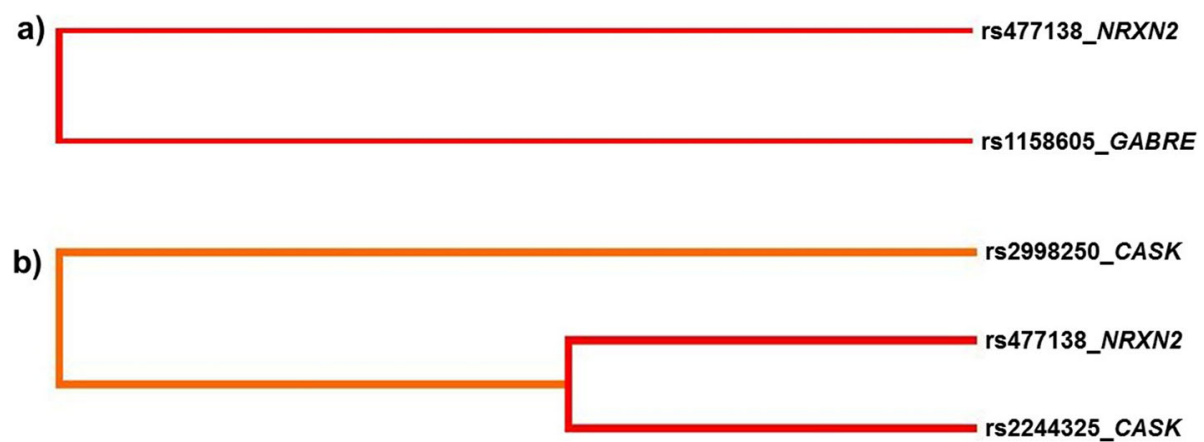

Fig. 1 Interaction dendrogram between a NRXN2-GABRE and $\mathbf{b}$ NXRN2-CASK in migraine susceptibility. The colour of the line indicates the type of interaction. Black and dark grey suggest a synergistic relationship. Shorter length of the lines shows a stronger interaction 
Table 3 Interaction results found between NRXN2*SYT1; NRXN2*CASK and NRXN2*GABRE, assessed by a logistic regression analysis

\begin{tabular}{|c|c|c|c|}
\hline Interaction & OR & Migraine $\mathrm{Cl} 95 \%$ & $P$-value \\
\hline \multicolumn{4}{|l|}{ NRXN2*SYT1 } \\
\hline rs477138*rs1732664 & & & 0.10 \\
\hline$C C^{*} T T$ & 1.00 & - & - \\
\hline $\mathrm{GC}^{*} \mathrm{CT}$ & 0.34 & $0.14-0.82$ & 0.02 \\
\hline \multicolumn{4}{|l|}{ NRXN2*CASK } \\
\hline rs477138*rs2244325*rs2998250 & & & 0.30 \\
\hline$C C^{*} A A^{*} A A$ & 1.00 & - & - \\
\hline $\mathrm{GG}^{*} \mathrm{GG}^{*} \mathrm{CC}$ & 0.08 & $0.01-0.75$ & 0.03 \\
\hline \multicolumn{4}{|l|}{ NRXN2*GABRE } \\
\hline rs477138*rs1158605 & & & 0.001 \\
\hline$C C^{*} G G$ & 1.00 & - & - \\
\hline$C G^{*} G T$ & 4.78 & $1.76-12.97$ & 0.002 \\
\hline
\end{tabular}

NRXN2 Neurexin II, SYT1 Synaptotagmin 1, GABRE Gamma-aminobutyric acid type $\mathrm{A}$ receptor epsilon subunit, $O R$ Odds ratio, $\mathrm{Cl}$ Confidence interval. ( $a=$ 0.02 , after Bonferroni correction)

multivariable-logistic regression indicated a significant possible protective effect $[\mathrm{OR}=0.34$ (95\%CI: $0.14-0.82$ ), $p=0.02$ ] (Table 3). However, as these results were not consistent between the two analyses, we did not presume an interaction between the SNPs evaluated in these two genes on migraine susceptibility.

\section{Discussion}

Migraine is a chronic and common neurological condition conceptualized as a complex genetic disorder [3]. This study aimed to investigate the role of genes coding for proteins involved in the control of neurotransmission in migraine susceptibility, thereby improving the knowledge of the mechanisms involved in this phenomenon.

We for the first time show that the genetic interaction and synergetic effect between variants in NRXN2, GABRE and CASK, affects migraine predisposition.

NRXN2 encodes neurexin II protein, one of three neurexin family members, which play a central role in presynaptic cell adhesion as well as binding intracellular and postsynaptic partners. Interaction in the synaptic cleft of neurexin and neuroligin results in the connection between the two neurons and the production of a synapse [13, 16]. Genetic abnormalities in the neurexinneuroligin complex leads to an imbalance of excitatory and inhibitory neurotransmission due to loss of presynaptic strength. Deletion of all neurexin family members is lethal and disease-causing variants in neurexin genes has been implicated in the pathomechanisms of schizophrenia and autism spectrum disorders [36].

Until now, no studies have associated this gene with migraine. We did not find any significant association between NRXN2 and migraine susceptibility in the allelic, genotypic and haplotypic analyses showing that this gene does not act as an independent factor in migraine etiology, in our sample.

\section{NRXN2 interactors}

However, and due to the high complexity of the synaptic vesicle machinery and neurotransmitter release, we decided to focus our analysis on the possible interactors of NRXN2. Importantly, we identified two substantial and significant interactions regarding NRXN2-GABRE and NRXN2-CASK.

Our analysis showed an increased risk for the female migraineurs that are double heterozygotes for rs 477138 (NRXN2) and rs1158605 (GABRE), when compared with the most common genotypes (Table 3).

GABRE is located in chromosome $\mathrm{X}$ and belongs to a cluster of GABA receptor genes, encoding for epsilon subunits. Studies carried on in rats show that the subunits are co-expressed in locus cœruleus as well as in other specific brain regions, and may be involved in the migraine [37]. Zhang et al. have shown that presynaptic neurexins physically and functionally interact on postsynaptic $\mathrm{GABA}_{\mathrm{A}}$ receptors, which may participate in the regulation of the inhibitory/excitatory balance in the brain [14].

Likewise, we also verified the evidence for genetic interaction between NRXN2 and CASK in migraine susceptibility. A significant interaction between rs477138 of NRXN2 and rs2244325 and rs2998250 of CASK was found in the female group, showing a protective effect of the rare homozygotes: GG, CC and GG, respectively (Table 3). The interaction of the CASK PDZ domain with neurexins has been demonstrated [38]; wherein CASK phosphorylates neurexin, although the functional relevance of this activity is still unclear [39]. Alternative splicing neurexin variants were shown to be coupled to synaptic activity via the CASK pathway [16], namely it has been revealed that the activation of the SS\#3 splice site in NRXN2 resulting in exon 11 exclusion depends on depolarization and $\mathrm{Ca} 2+$ influx [13]. It is also important to address that disease-causing variants in genes encoding $\mathrm{Ca} 2+$ channel subunits result in familial hemiplegic migraine, a monogenic subtype of migraine [40]. Lastly, even though a biological link has been shown between proteins such as SYT through the binding to the disordered carboxyterminal domain of neurexins [15], our results do not establish a role for their genetic interaction in migraine susceptibility.

\section{Gene-gene interactions}

Indication of genetic interaction in migraine predisposition has been previously shown, namely, our group had found a robust gene-gene interaction between $B D N F$ and CGRP and between $G A B A_{A} R$ genes, in migraine susceptibility $[19,23]$. These studies reinforce the 
importance of investigating interactions among candidate genes in migraine pathophysiology and also support the genetic interplay in the susceptibility of this disorder.

We performed a logistic regression, including interaction terms considering the NRXN2-GABRE and NRXN2-CASK SNPs, in an exploratory-driven analysis of a potential interaction between these gene pairs. The limited number of subjects in each group may impair the estimation of logistic regression parameters thus we chose to perform a MDR analysis. This method combines genotypes into a single dimension with two groups (high or low risk). MDR is also capable of detecting a high-order interaction even in the absence of a main effect with statistical significance. Furthermore, the frequency of false positive results is minimized by the combination of permutation testing and cross-validation [34]. Additionally, MDR has the capability to detect gene-gene interactions even with smaller sample sizes [41], which bestows confidence in our results. All of our interactions were also reaffirmed by a 1000 -fold permutation test.

Despite our results being only significant for the female group, differences between genders cannot alone be explained by the influence of X-chromosome genes. Both male and female sex hormones are expected to have a critical impact on the course of the disease. Although the relationship between estrogen and migraine is complex, involving modulation by genomic and nongenomic effects, it is involved, among many other mechanisms, in pain pathways [42]. On the other hand, progesterone appears to have a protective role which might decrease the occurrence of migraine [43]. Likewise, testosterone acts in men as a protective mechanism in the development of pain [43]. These facts may also be responsible for the differential gender ratio found in this disorder but it would be important to assess to what extent our results reflect a true gender-specific effect versus a lower prevalence of migraine in males [44]. However, we should not overlook that practical applications will require more in-depth studies to better understand the pathophysiological mechanisms of migraine.

In conclusion, we found a very significant (two-way) interaction in females between NRXN2-GABRE and NRXN2-CASK associated with migraine susceptibility. Based on these results, we hypothesized a convergence of genotypes in these genes associated with migraine susceptibility.

From a clinical point of view, we believe that our study provides important insights in gender-liability differences in migraine. To confirm these results, further studies are needed. Neurogenic mechanisms have been described in previous studies as involved in migraine, including in recent GWAS and also in transgenic mouse models studies [6, 7]. Although GWAS represent a major step in identifying the polygenetic nature of migraine, these large-scale studies typically have a modest impact on interpreting the contribution of any implicated gene to migraine pathophysiology.

\section{Conclusions}

Until now, no studies have aimed at associating the neurexin genes with migraine. The involvement of $N R X N 2$ gene in migraine is reported for the first time in this study, allowing new hypotheses to be generated that can be translated into new GWA and functional studies to reveal the its underlying biological mechanisms. These gene interactions may be part of a larger network of genes that will help to solve the immense puzzle of the complex etiology of migraine and open the door to novel therapeutic approaches.

\section{Abbreviations}

CASK: Calcium/calmodulin-dependent serine protein kinase; CNS: Central nervous system; CVC: Cross-validation consistency; FDR: False Discovery Rate; GABA: Gamma-aminobutyric acid; GABRE: Gamma-aminobutyric acid type A receptor epsilon subunit; GWAS: Genome-wide association studies; MAF: Minor allele frequency; MDR: Multifactor Dimensionality Reduction; NRXN2: Neurexin; NSF: N-ethylmaleimide-sensitive factor; SNPS: Single nucleotide polymorphisms; SYT: Synaptotagmin; TBA: Testing balanced accuracy

\section{Supplementary Information}

The online version contains supplementary material available at https://doi. org/10.1186/s10194-021-01266-y

Additional file 1: Additional Table 1. Allelic association analysis of tagging SNPs selected for NRXN2 gene.

Additional file 2: Additional Table 2. Genotypic association of tagging SNPs selected for NRXN2 gene by multivariable logistic regression analysis.

Additional file 3: Additional Table 3. Haplotype association analysis of tagging SNPS selected for NRXN2 gene.

\section{Acknowledgements}

It is with deep regret and profound sadness that we would like to inform you that one of our co-authors, professor Pereira-Monteiro, passed away last month. He was a very well-known neurologist and one of the leading national headache specialists and his reputation in this area extended internationally. We worked with Professor Pereira-Monteiro within the last 20 years and his clinical contribution to this study was fundamental.

We acknowledge all patients and non-migraineur controls for being part of this study.

\section{Authors' contributions}

Conception and design: IA, JLN, CL. Acquisition of data: JPM. Analysis and interpretation of data: MAF, MQ, AS, IA, CL. Drafting the manuscript: MAF. Revising it for intellectual content: MQ, JS, AS, JPM, IA, JLN, CL. Final approval of manuscript: All authors.

\section{Funding}

This work was funded by Sociedade Portuguesa de Cefaleias (SPC), Fundação para a Ciência e Tecnologia (FCT; PTDC/MEC-NEU/29468/2017), Tecnifar fellowships and by European Commission and European Regional Development Fund under the project 'Análisis y correlación entre la epigenética y la actividad cerebral para evaluar el riesgo de migraña crónica y episódica en mujeres' (Cooperation Programme Interreg V-A SpainPortugal, POCTEP 2014-2020, by the Ministerio de Ciencia, Innovación y Universidades). 


\section{Availability of data and materials}

The datasets used and/or analysed during the current study are available from the corresponding author on reasonable request.

\section{Declarations}

\section{Ethics approval and consent to participate}

The Ethics Committee of Hospital de Santo António - Centro Hospitalar Universitário do Porto approved the study and participants were asked to give their written informed consent to take part in the study.

\section{Consent for publication}

Not applicable.

\section{Competing interests}

The authors declared no potential conflicts of interest to disclose.

\section{Received: 10 December 2020 Accepted: 25 May 2021}

Published online: 14 June 2021

\section{References}

1. Disease GBD, Injury I, Prevalence C (2017) Global, regional, and national incidence, prevalence, and years lived with disability for 328 diseases and injuries for 195 countries, 1990-2016: a systematic analysis for the global burden of Disease study 2016. Lancet. 390(10100):1211-1259

2. Steiner TJ, Stovner LJ, Vos T (2016) GBD 2015: migraine is the third cause of disability in under 50s. J Headache Pain 17(1):104. https://doi.org/10.1186/s1 0194-016-0699-5

3. Wessman M, Terwindt GM, Kaunisto MA, Palotie A, Ophoff RA (2007) Migraine: a complex genetic disorder. Lancet Neurol 6(6):521-532. https:// doi.org/10.1016/S1474-4422(07)70126-6

4. Russell MB, Olesen J (1995) Increased familial risk and evidence of genetic factor in migraine. BMJ. 311(7004):541-544. https://doi.org/10.1136/bmj.311. 7004.541

5. Lemos C, Castro MJ, Barros J, Sequeiros J, Pereira-Monteiro J, Mendonca D et al (2009) Familial clustering of migraine: further evidence from a Portuguese study. Headache. 49(3):404-411. https://doi.org/10.1111/j.1526-4 610.2008.01177.x

6. Meng W, Adams MJ, Hebert HL, Deary IJ, Mclntosh AM, Smith BH (2018) A genome-wide association study finds genetic associations with broadlydefined headache in UK biobank $(N=223,773)$. EBioMedicine. 28:180-186. https://doi.org/10.1016/j.ebiom.2018.01.023

7. Gormley P, Winsvold BS, Nyholt DR, Kallela M, Chasman DI, Palotie A (2016) Migraine genetics: from genome-wide association studies to translational insights. Genome Med 8(1):86. https://doi.org/10.1186/s13073-016-0346-4

8. de Vries B, Anttila V, Freilinger T, Wessman M, Kaunisto MA, Kallela M, Artto V, Vijfhuizen LS, Göbel H, Dichgans M, Kubisch C, Ferrari MD, Palotie A, Terwindt GM, van den Maagdenberg A, International Headache Genetics Consortium (2016) Systematic re-evaluation of genes from candidate gene association studies in migraine using a large genome-wide association data set. Cephalalgia. 36(7):604-614. https://doi.org/10.1177/0333102414566820

9. Neto $J \mathrm{~L}$ (2010) The role of synaptic vesicles' molecular machinery encoding genes in migraine susceptibility [master thesis]. University of Porto, Porto

10. Lemos C, Pereira-Monteiro J, Mendonca D, Ramos EM, Barros J, Sequeiros J et al (2010) Evidence of syntaxin 1A involvement in migraine susceptibility: a Portuguese study. Arch Neurol 67(4):422-427. https://doi.org/10.1001/a rchneurol.2010.37

11. Quintas M (2012) Migraine susceptibility: the role for the X-chromosome genes. University of Porto, Porto

12. Zhang W, Rohlmann A, Sargsyan V, Aramuni G, Hammer RE, Sudhof TC et al (2005) Extracellular domains of alpha-neurexins participate in regulating synaptic transmission by selectively affecting $\mathrm{N}$ - and P/Q-type Ca2+ channels. J Neurosci 25(17):4330-4342. https://doi.org/10.1523/JNEUROSCI. 0497-05.2005

13. Reissner C, Runkel F, Missler M (2013) Neurexins. Genome Biol 14(9):213. https://doi.org/10.1186/gb-2013-14-9-213

14. Zhang C, Atasoy D, Arac D, Yang X, Fucillo MV, Robison AJ et al (2010) Neurexins physically and functionally interact with GABA(a) receptors. Neuron. 66(3):403-416. https://doi.org/10.1016/j.neuron.2010.04.008

15. O'Connor VM, Shamotienko O, Grishin E, Betz H (1993) On the structure of the 'synaptosecretosome'. Evidence for a neurexin/synaptotagmin/syntaxin/
Ca2+ channel complex. FEBS Lett 326(1-3):255-260. https://doi.org/10.1016/ 0014-5793(93)81802-7

16. Sudhof TC (2017) Synaptic Neurexin complexes: a molecular code for the logic of neural circuits. Cell. 171(4):745-769. https://doi.org/10.1016/j.cell.201 7.10 .024

17. Sarang SS, Lukyanova SM, Brown DD, Cummings BS, Gullans SR, Schnellmann RG (2008) Identification, coassembly, and activity of gammaaminobutyric acid receptor subunits in renal proximal tubular cells. J Pharmacol Exp Ther 324(1):376-382. https://doi.org/10.1124/jpet.107.129957

18. Owens DF, Kriegstein AR (2002) Is there more to GABA than synaptic inhibition? Nat Rev Neurosci 3(9):715-727. https://doi.org/10.1038/nrn919

19. Quintas M, Neto JL, Pereira-Monteiro J, Barros J, Sequeiros J, Sousa A, Alonso I, Lemos C (2013) Interaction between gamma-aminobutyric acid a receptor genes: new evidence in migraine susceptibility. PLoS One 8(9): e74087. https://doi.org/10.1371/journal.pone.0074087

20. Puppe A, Limmroth V (2007) GABAergic drugs for the treatment of migraine. CNS Neurol Disord Drug Targets 6(4):247-250. https://doi.org/1 $0.2174 / 187152707781387305$

21. Hsueh YP (2006) The role of the MAGUK protein CASK in neural development and synaptic function. Curr Med Chem 13(16):1915-1927. https://doi.org/10.2174/092986706777585040

22. Spafford JD, Zamponi GW (2003) Functional interactions between presynaptic calcium channels and the neurotransmitter release machinery. Curr Opin Neurobiol 13(3):308-314. https://doi.org/10.1016/S0959-4388(03 )00061-8

23. Lemos C, Mendonca D, Pereira-Monteiro J, Barros J, Sequeiros J, Alonso I et al (2010) BDNF and CGRP interaction: implications in migraine susceptibility. Cephalalgia. 30(11):1375-1382. https://doi.org/10.1177/03331 02410368443

24. Kowalska M, Prendecki M, Kozubski W, Lianeri M, Dorszewska J (2016) Molecular factors in migraine. Oncotarget. 7(31):50708-50718. https://doi. org/10.18632/oncotarget.9367

25. Headache Classification Subcommittee of the International Headache Society. The International Classification of Headache Disorders: 2nd edition. Cephalalgia. 2004;24 Suppl 1:9-160. https://doi.org/10.1111/j.1468-2982.2003. 00824.x.

26. Headache Classification Committee of the International Headache Society (IHS) The International Classification of Headache Disorders, 3rd edition. Cephalalgia. 2018;38(1):1-211. https://doi.org/10.1177/0333102417738202.

27. Miller SA, Dykes DD, Polesky HF (1988) A simple salting out procedure for extracting DNA from human nucleated cells. Nucleic Acids Res 16(3):1215. https://doi.org/10.1093/nar/16.3.1215

28. Barrett JC, Fry B, Maller J, Daly MJ (2005) Haploview: analysis and visualization of LD and haplotype maps. Bioinformatics. 21(2):263-265. https://doi.org/10.1093/bioinformatics/bth457

29. Morcillo-Suarez C, Alegre J, Sangros R, Gazave E, de Cid R, Milne R, Amigo J, Ferrer-Admetlla A, Moreno-Estrada A, Gardner M, Casals F, Perez-Lezaun A Comas D, Bosch E, Calafell F, Bertranpetit J, Navarro A (2008) SNP analysis to results (SNPator): a web-based environment oriented to statistical genomics analyses upon SNP data. Bioinformatics. 24(14):1643-1644. https://doi.org/1 0.1093/bioinformatics/btn241

30. Szklarczyk D, Gable AL, Lyon D, Junge A, Wyder S, Huerta-Cepas J, Simonovic M, Doncheva NT, Morris JH, Bork P, Jensen LJ, Mering C (2019) STRING v11: protein-protein association networks with increased coverage, supporting functional discovery in genome-wide experimental datasets. Nucleic Acids Res 47(D1):D607-DD13. https://doi.org/10.1093/nar/gky1131

31. Ashburner M, Ball CA, Blake JA, Botstein D, Butler H, Cherry JM, Davis AP, Dolinski K, Dwight SS, Eppig JT, Harris MA, Hill DP, Issel-Tarver L, Kasarskis A, Lewis S, Matese JC, Richardson JE, Ringwald M, Rubin GM, Sherlock G (2000) Gene ontology: tool for the unification of biology. The Gene Ontology Consortium. Nat Genet 25(1):25-29. https://doi.org/10.1038/75556

32. The Gene Ontology Consortium (2019) The Gene Ontology Resource: 20 years and still GOing strong. Nucleic Acids Res 47(D1):D330-D3D8

33. Lai $Y$ (2017) A statistical method for the conservative adjustment of false discovery rate (q-value). BMC Bioinformatics 18(Suppl 3):69. https://doi.org/1 0.1186/s12859-017-1474-6

34. Moore JH (2004) Computational analysis of gene-gene interactions using multifactor dimensionality reduction. Expert Rev Mol Diagn 4(6):795-803. https://doi.org/10.1586/14737159.4.6.795

35. Heidema AG, Feskens EJ, Doevendans PA, Ruven HJ, van Houwelingen HC, Mariman EC et al (2007) Analysis of multiple SNPs in genetic association 
studies: comparison of three multi-locus methods to prioritize and select SNPs. Genet Epidemiol 31(8):910-921. https://doi.org/10.1002/gepi.20251

36. Sudhof TC (2008) Neuroligins and neurexins link synaptic function to cognitive disease. Nature. 455(7215):903-911. https://doi.org/10.1038/na ture07456

37. Andreou AP, Shields KG, Goadsby PJ (2010) GABA and valproate modulate trigeminovascular nociceptive transmission in the thalamus. Neurobiol Dis 37(2):314-323. https://doi.org/10.1016/j.nbd.2009.10.007

38. Hata Y, Butz S, Sudhof TC (1996) CASK: a novel dlg/PSD95 homolog with an $\mathrm{N}$-terminal calmodulin-dependent protein kinase domain identified by interaction with neurexins. J Neurosci 16(8):2488-2494. https://doi.org/10.1 523/JNEUROSCl.16-08-02488.1996

39. LaConte LE, Chavan V, Liang C, Willis J, Schonhense EM, Schoch S et al (2016) CASK stabilizes neurexin and links it to liprin-alpha in a neuronal activity-dependent manner. Cell Mol Life Sci 73(18):3599-3621. https://doi. org/10.1007/s00018-016-2183-4

40. Pietrobon D (2002) Calcium channels and channelopathies of the central nervous system. Mol Neurobiol 25(1):31-50. https://doi.org/10.1385/MN:25:1: 031

41. Ritchie MD, Hahn LW, Moore JH (2003) Power of multifactor dimensionality reduction for detecting gene-gene interactions in the presence of genotyping error, missing data, phenocopy, and genetic heterogeneity. Genet Epidemiol 24(2):150-157. https://doi.org/10.1002/gepi.10218

42. Paredes S, Cantillo S, Candido KD, Knezevic NN (2019) An Association of Serotonin with Pain Disorders and Its Modulation by Estrogens. Int J Mol Sci 20(22):5729

43. Cairns BE, Gazerani P (2009) Sex-related differences in pain. Maturitas. 63(4): 292-296. https://doi.org/10.1016/j.maturitas.2009.06.004

44. Vetvik KG, MacGregor EA (2017) Sex differences in the epidemiology, clinical features, and pathophysiology of migraine. Lancet Neurol 16(1):76-87. https://doi.org/10.1016/S1474-4422(16)30293-9

\section{Publisher's Note}

Springer Nature remains neutral with regard to jurisdictional claims in published maps and institutional affiliations.

Ready to submit your research? Choose BMC and benefit from:

- fast, convenient online submission

- thorough peer review by experienced researchers in your field

- rapid publication on acceptance

- support for research data, including large and complex data types

- gold Open Access which fosters wider collaboration and increased citations

- maximum visibility for your research: over $100 \mathrm{M}$ website views per year

At $\mathrm{BMC}$, research is always in progress.

Learn more biomedcentral.com/submissions 